\title{
Correction to: Intravenous Migraine Treatment in Children and Adolescents
}

\author{
Klaus G. Werner ${ }^{1}$ D - Sharoon Qaiser ${ }^{2} \cdot$ Marielle A. Kabbouche ${ }^{2} \cdot$ Beverly Murphy $^{3} \cdot$ Ian Maconochie ${ }^{4}$. \\ Andrew D. Hershe ${ }^{2}$
}

Published online: 11 August 2020

(C) Springer Science+Business Media, LLC, part of Springer Nature 2020

\section{Correction to: Current Pain and Headache Reports (2020) 24:45} https://doi.org/10.1007/s11916-020-00867-7

The original publication of this article unfortunately contained the incorrect version of the manuscript. The original article has been corrected.

Publisher's Note Springer Nature remains neutral with regard to jurisdictional claims in published maps and institutional affiliations.

The online version of the original article can be found at https://doi.org/ 10.1007/s11916-020-00867-7

$\triangle$ Klaus G. Werner

klaus.werner@duke.edu

Sharoon Qaiser

Sharoon.Qaiser@cchmc.org

1 Division of Pediatric Neurology, Duke University Medical Center, Durham, NC 27710, USA

2 Division of Neurology, Cincinnati Children's Hospital Medical Center, University of Cincinnati College of Medicine, E4-310, 3333 Burnet Avenue, Cincinnati, OH 45229, USA

3 Medical Center Library \& Archives, Duke University Medical Center, Durham, NC 27710, USA

4 Imperial College NHS Healthcare Trust, London, UK 